\title{
CARACTERÍSTICAS DAS EMPRESAS E DOS GESTORES QUE INFLUENCIAM O USO DE CONTROLES GERENCIAIS
}

\author{
Vanderlei dos Santos' \\ Ilse Maria Beuren ${ }^{2}$ \\ Norton Luis Corrêa ${ }^{3}$ \\ Layla Beatriz Boos Martins ${ }^{4}$
}

Resumo: O estudo objetiva identificar características das empresas e dos gestores que influenciam o uso de controles gerenciais. Pesquisa descritiva com abordagem quantitativa foi realizada por meio de um levantamento, tendo como amostra 37 empresas industriais que responderam o instrumento de pesquisa. Na análise dos dados utilizaram-se técnicas de estatística descritiva, correlação de Spearman e testes não paramétricos de Mann-Whitney e Kruskal-Wallis. Os resultados apontam que o custeio por absorção, o planejamento tributário e o benchmarking figuram entre os controles mais utilizados pelas empresas pesquisadas. Não se observa diferenças significativas entre o uso de instrumentos tradicionais e modernos da Contabilidade Gerencial. Os controles tradicionais apresentaram maior intensidade de uso nas empresas tributadas pelo lucro real, que estão na primeira geração familiar e com gestores que possuem nível superior. Já os controles modernos são mais utilizados pelas empresas familiares com gestores mais jovens, que possuem ensino superior na área de negócios. Conclui-se que escolaridade e idade do gestor são as principais características que se refletem no maior uso de controles modernos e que as empresas familiares apresentam-se diferenciadas no uso de controles gerenciais, o que instiga novas pesquisas para possíveis explicações organizacionais e/ou comportamentais, de modo a compreender de forma holística as implicações do uso dos controles gerenciais.

Palavras-chave: Controles gerenciais. Características das empresas. Perfil dos gestores.

\footnotetext{
vanderleidossantos09@gmail.com - Universidade Federal de Santa Catarina. Universidade do Estado de Santa Catarina.

2 ilse.beuren@gmail.com - Universidade Federal de Santa Catarina

3nc.nortoncorrea@gmail.com - Universidade do Estado de Santa Catarina

${ }^{4}$ laylaboos@gmail.com - Universidade do Estado de Santa Catarina 


\section{CHARACTERISTICS OF COMPANIES AND MANAGERS THAT INFLUENCE THE USE OF MANAGEMENT CONTROLS}

Abstract: The goal of the study is to identify the characteristics of companies and managers that influence the use of management controls. Descriptive research with quantitative approach was conducted through a survey, having as sample 37 industrial companies which answered the survey instrument. The questionnaire comprised six characteristics of the companies and two characteristics of the managers, and also twenty assertions concerning management controls, based on studies of Soutes (2006), Correia (2010) and Valeriano (2012). The techniques of descriptive statistics, Spearman correlation and the nonparametric Mann-Whitney and Kruskal-Wallis were used to analyze the data. The results show that the absorption costing, tax planning and benchmarking are among the most used controls in the companies surveyed. No significant differences were observed between the use of traditional and modern instruments of Management Accounting. Traditional controls showed greater intensity of use in companies taxed by real profit, which are in the first generation of the family and with managers who have higher education. Modern controls, on the other hand, are more commonly used by family businesses with younger managers who have higher education in the business area. It is concluded that managers' education and age are the main characteristics that are reflected on the increased use of modern controls and that family companies have become differentiated in the use of management controls, which instigates new research for possible organizational and/or behavioral explanations, in order to holistically understand the implications of the use of management controls.

Keywords: Management controls. Companies characteristics. Managers profile. 


\section{INTRODUÇÃO}

E studos com o objeto de investigar o nível de aderência do uso de controles tradicionais versus modernos proliferaram, principalmente, a partir da década de 1990 (Sulaiman, Ahmad \& Alwi, 2004; Frezatti, 2005; Angelakis,Theriou \& Floropoulos, 2010; Teixeira, Gonzaga, Santos \& Nossa, 2011; Reis \& Teixeira, 2013), sua relação com o tamanho (Frezatti, 2005; Abdel-Kader \& Luther, 2008; Guerreiro,Cornachione Júnior \& Soutes, 2011; Reis \& Teixeira, 2013), com o desempenho financeiro (Soutes, 2006; Teixeira et al. 2011; Reis \& Teixeira, 2013) e com outras variáveis contingenciais e/ou fatores institucionais (Chenhall \& Langfield-Smith, 1998; Abdel-Kader \& Luther, 2008; Oyadomari, Cardoso, Mendonça Neto \& Lima, 2008; Pavlatos, 2012), além de características dos gestores (Naranjo-Gil, Maas \& Hartmaan, 2009; Pavlatos, 2012).

Os primeiros aspectos destes estudos, de acordo com El-Shishini (2017), concentraram-se em descrever e relatar os instrumentos da Contabilidade Gerencial adotados pelas organizações, comparar a adoção destes instrumentos entre países e descrever os seus benefícios e as intenções de uso no futuro. Nessa categoria enquadram-se as pesquisas realizadas por Chenhall e Langfield-Smith (1998) em empresas de manufatura australianas; Sulaiman, Ahmad e Alwi (2004), que compararam a adoção de instrumentos tradicionais e modernos em quatro países asiáticos; Abdel-Kader e Luther (2006), que abarcaram as empresas do Reino Unido; e Yalcin (2012) em empresas localizadas na Turquia.

Outra corrente de estudos investigou a relação entre variáveis contextuais e práticas da Contabilidade Gerencial (El-Shishini, 2017). Nesta perspectiva, Chenhall e Langfield-Smith (1998) e Davila e Foster (2007) asseveram que há evidências consideráveis de que o tamanho é um fator que influencia a adoção de sistemas de gestão mais complexos. Desse modo, a Contabilidade Gerencial pode ser afetada por características internas ou externas à organização, tais como: cultura nacional, estrutura interna, taxa de crescimento interna, estratégia organizacional, experiência do gestor e tamanho da empresa (Gonzaga, Luz, Guimarães \& Valério Jr., 2010). Otley (1980) já asseverava de que não há um único sistema de controle que possa ser aplicado, igualmente, a todas as organizações e em todas as circunstâncias, isso dependerá da necessidade de cada organização para um determinado momento.

Naranjo-Gil, Maas e Hartmann (2009) mencionam que as pesquisas deste grupo utilizaram duas perspectivas distintas para explicar o motivo de muitas organizações não utilizar práticas avançadas da Contabilidade Gerencial, apesar da aparente superioridade técnica. Esses autores ressaltam que alguns estudos utilizaram a Teoria da Contingência para explicar as decisões de adoção de inovação e processos de implementação subsequente de instrumentos gerenciais. Estas pesquisas preconizam que as contingências organizacionais e ambientais determinam o grau em que as organizações se beneficiam ao implementar práticas da Contabilidade Gerencial inovadoras e (implicitamente) assumem que a decisão de inovar reflete um trade-off racional entre os custos e os benefícios esperados.

Outros pesquisadores, segundo Naranjo-Gil, Maas e Hartmann (2009), enfatizam que a adaptação racional às circunstâncias ambientais não pode explicar completamente a adoção e o uso de novas práticas da Contabilidade Gerencial e apontam para fatores institucionais e gerenciais que vão além do trade-off racional dos custos esperados e benefícios da inovação. Nesta perspectiva, a adoção e o uso de novos sistemas de gestão exigem que os gestores responsáveis reconheçam a necessidade de inovação e iniciem as mudanças necessárias (Naranjo-Gil, Maas \& Hartmann, 2009). A presente pesquisa perpassa essa perspectiva. 
Neste estudo, investigam-se características das empresas e dos gestores que podem se refletir em diferenças no uso dos controles tradicionais e modernos da Contabilidade Gerencial. Desse modo, a questão problema que norteia a pesquisa é: Características das empresas (faturamento, regime de tributação, empresa familiar, geração familiar e tempo de empresa) e dos gestores (escolaridade, formação acadêmica e idade) implicam diferenças no uso de controles tradicionais e modernos da Contabilidade Gerencial em empresas industriais brasileiras? Portanto, este estudo objetiva identificar as características das empresas e dos gestores que influenciam o uso de controles gerenciais.

Evidências teórico-empíricas mostram que o uso de instrumentos modernos da Contabilidade Gerencial varia entre organizações e entre setores econômicos (Naranjo-Gil, Maas \& Hartmaan, 2009), o que instiga a realização de pesquisas explicativas desse fenômeno. Chenhall e Langfield-Smith (1998) advertem que pesquisas futuras devem ser direcionadas para obter uma melhor compreensão dos fatores que influenciam diferenças nos níveis de adoção de instrumentos modernos da Contabilidade Gerencial. Assim, a presente pesquisa justifica-se como forma de contribuição aos estudos realizados, ao considerar empresas industriais brasileiras.

No entanto, diferente de estudos que contemplaram de forma isolada algumas características empresariais, nesta pesquisa aborda-se em conjunto os reflexos do faturamento, regime de tributação, empresa familiar versus não familiar, além de características dos gestores no uso de controles gerenciais. Naranjo-Gil, Maas e Hartmaan (2009) mencionam que, embora a literatura reconheça amplamente que as características dos gestores são preditivas de resultados organizacionais, pouco se sabe sobre como as diferenças gerenciais individuais afetam o desenho dos sistemas de contabilidade e de controle. Várias pesquisas (Frezatti, 2005; Gonzaga et al., 2010; Guerreiro, Cornachione Júnior \& Soutes, 2011) se ativeram à variável porte para explicar as diferenças no uso de instrumentos gerenciais.

Neste estudo ainda relaciona-se estas características com a intensidade de uso dos instrumentos gerenciais. Alguns estudos nacionais (Reis \& Teixeira, 2013) investigaram se determinados instrumentos são usados, sem verificar a intensidade de uso. Pavlatos e Kostakis (2015) observaram que a crise na Grécia levou a uma análise mais profunda das empresas em relação ao seu ambiente externo e pontos fortes e fracos, o que se refletiu em mudanças no uso dos instrumentos gerenciais. Em analogia, o cenário econômico e político do Brasil também pode influenciar a intensidade de uso dos instrumentos.

\section{REVISÃO DA LITERATURA}

\subsection{Contabilidade Gerencial e controles gerenciais}

De acordo com o CGMA ${ }^{\oplus}$ (2016, p. 8), "a Contabilidade Gerencial é fonte, análise, comunicação e uso da informação financeira e não financeira relevante para a decisão, com o objetivo de gerar e preservar valor para as organizações". De forma ampla, a Contabilidade Gerencial pode ser considerada como um mecanismo de auxílio à sobrevivência das organizações. Para tanto, faz-se uso de controles gerenciais, sendo que estes podem ser divididos em tradicionais e modernos, além da classificação em estágios proposta pelo International Management Accounting Practice - IMAP 1 (Reis \& Teixeira, 2013).

Chenhall (2003) adverte que os termos Contabilidade Gerencial, Sistemas de Contabilidade Gerencial, Sistema de Controle Gerencial (SCG) e controles organizacionais são por vezes utilizados indistintamente. Para o autor, a Contabilidade Gerencial refere-se a um conjunto de práticas, como, orçamento ou custo do produto. Enquanto que Sistemas de Contabilidade Gerencial referem-se ao uso sistemático da Contabilidade Gerencial para atingir alguma meta. Ao passo que o SCG é um termo mais amplo, que engloba 
Sistemas de Contabilidade Gerencial e outros controles. Já os controles organizacionais referem-se aos incorporados em atividades e processos, como, controle de qualidade. Denota-se que o SCG abarca os instrumentos da Contabilidade Gerencial, objeto de investigação deste estudo.

Os instrumentos tradicionais da Contabilidade Gerencial são orientados para uso interno e financeiro, com foco no curto prazo (Chenhall \& Langfield-Smith, 1998). Foram desenvolvidos antes da década de 1980, e incluem o custeio por absorção, custeio variável, custo padrão, retorno sobre o investimento (Nuhu, Baird \& Appuhami, 2016). Chenhal e Langfield-Smith (1998) explicam que os instrumentos tradicionais da Contabilidade Gerencial são aqueles relacionados aos sistemas orçamentários, avaliação e mensuração de desempenho, relatórios de resultados departamentais, planejamento e controle e análises da relação custo-volume-lucro.

Em contraste, os instrumentos da Contabilidade Gerencial mais contemporâneos (modernos) combinam informações financeiras e não financeiras e assumem um foco estratégico explícito. Isso pode ser visto, por exemplo, na concepção do custeio baseado em atividades, sistemas de medição de desempenho contemporâneos e técnicas de benchmarking (Chenhall \& Langfield-Smith, 1998). De acordo com Chenhall e Langfield-Smith (1998) e Hyvönen (2005), os instrumentos modernos da Contabilidade Gerencial são considerados como práticas que têm a capacidade de relacionar operações, processos e/ou atividades com resultados estratégicos. Eles também se concentram tanto em eventos históricos como futuros, e são de natureza interorganizacional (Abdel-Kader \& Luther 2006).

Para Abdel-Kader e Luther (2006), os instrumentos modernos da Contabilidade Gerencial afetaram todo o processo da Contabilidade Gerencial (planejamento, controle, tomada de decisão e comunicação), o que mudou seu foco de um papel simples de determinação de custos e controle financeiro, para um papel sofisticado de criação de valor por meio de um melhor uso de recursos. Neste sentido, diversos estudos sobre controles gerenciais tradicionais versus modernos vêm sendo realizados nos últimos anos.

Ao mapear e cotejar pesquisas internacionais (ex: Chenhall \& Langfield-Smith, 1998; Sulaiman, Ahmad \& Alwi, 2004; Abdel-Kader \& Luther, 2006; Naranjo-Gil, Maas \& Hartmaan, 2009; Pavlatos \& Kostakis, 2015; El-Shishini, 2017) com nacionais (ex: Frezatti, 2005; Raupp, Martins \& Beuren, 2006; Gonzaga et al., 2010; Guerreiro, Cornachione Júnior \& Soutes, 2011; Reis \& Teixeira, 2013), observa-se que a classificação dos instrumentos da Contabilidade Gerencial é mais homogênea em âmbito internacional, visto que as pesquisas os classificam em tradicionais e modernos. Também há estudos que abarcam os instrumentos por categorias/práticas, tais como: contabilidade de custos, planejamento e orçamento, sistemas de apoio à decisão, avaliação de desempenho e análise estratégica. Dentro destas práticas, há instrumentos tradicionais e modernos. Por exemplo, na classificação da prática de avaliação de desempenho, presente no estudo de Pavlatos e Kostakis (2015), há retorno sobre o ativo (tradicional) e BSC (moderno). A segregação dos instrumentos gerenciais por estágios evolutivos é preponderante em pesquisas nacionais, embora no documento da IFAC não tenha o detalhamento de quais instrumentos da Contabilidade Gerencial pertencem a cada estágio.

Foi constatado também que existem diferentes nomenclaturas para designar os instrumentos ou as práticas da Contabilidade Gerencial, principalmente em âmbito nacional. Alguns estudos denominaram-nos de controles de gestão (Raupp, Martins \& Beuren, 2006), outros de artefatos gerenciais (Guerreiro, Cornachione Júnior \& Soutes 2011). A listagem dos instrumentos também é variada. Verifica-se ainda que o tamanho da amostra é maior em pesquisas internacionais, o que pode ser uma evidência da dificuldade de realização deste tipo de pesquisas em âmbito nacional. A maioria das pesquisas nacionais investigou empresas listadas no ranking das Maiores e Melhores da Revista Exame. 
As pesquisas tiveram como foco o nível de adoção, intensidade de uso dos instrumentos e seus respectivos benefícios. Também algumas pesquisas foram realizadas com o intuito de obter explicações para o uso destes instrumentos. No presente estudo, investiga se características das empresas (faturamento, regime de tributação, empresa familiar, geração familiar e tempo de empresa) e dos gestores (escolaridade, formação e idade) implicam em diferenças no uso de controles tradicionais e modernos da Contabilidade Gerencial.

Em âmbito nacional, observa-se que os estudos realizados por Frezatti (2005), Gonzaga et al. (2010), Guerreiro, Cornachione Júnior e Soutes (2011), Isidoro et al. (2012), Reis e Teixeira (2013), analisaram a relação do porte da empresa com o uso dos instrumentos gerenciais. Contudo, não foram efetuadas associações com as características dos gestores, já observadas em pesquisas realizadas em âmbito internacional, como de Naranjo-Gil, Maas e Hartmaan (2009), Pavlatos (2010), Pavlatos (2012), o que instiga a realização de mais pesquisas.

\subsection{Características das empresas que afetam o uso de controles gerenciais}

Chenhall e Langfield-Smith (1998) mencionam que há evidências consideráveis de que o tamanho da organização é um fator que influencia a adoção de sistemas de gestão mais complexos, particularmente a adoção de instrumentos modernos da Contabilidade Gerencial. De acordo com os autores, um dos motivos para as grandes empresas adotarem os instrumentos modernos da Contabilidade Gerencial é o acesso relativamente maior aos recursos para experimentar inovações administrativas. Como grandes organizações tendem a ter mais recursos para o desenvolvimento de inovações, é provável que elas possam experimentar mais com sistemas de contabilidade inovadores (Chenhall \& Langfield-Smith, 1998).

Quando uma organização torna-se maior, aumenta a necessidade dos gestores lidar com uma maior quantidade de informações, o que exige a instituição de controles, como: regras, documentação, especialização de papéis e funções, descentralização (Chenhall, 2003). Davila (2005) explica que nos estágios iniciais de uma empresa, o controle e a coordenação ocorrem por meio de interações frequentes e informais. À medida que a empresa cresce, sua atenção se desloca para o desenvolvimento de sistemas que ancoram interações informais em torno de um conjunto de sistemas formalizados. Estes sistemas são necessários para fornecer a infraestrutura de gerenciamento que suporta o crescimento para além do estágio informal (Davila \& Foster, 2005).

Frezatti (2005) e Angelakis, Theriou e Floropoulos (2010) também constataram associações entre o porte da empresa (tamanho) e maior aderência de uso de instrumentos gerenciais, especificamente os ditos modernos. No presente estudo, o porte da empresa é operacionalizado por meio das variáveis faturamento e regime de tributação. Outra característica que pode influenciar no uso diferenciado de controles gerenciais é o tempo de constituição da empresa. Davila (2005) comenta que a idade da empresa atua na aprendizagem, que resulta em experiência de maneira semelhante aos mecanismos que governam a curva de aprendizagem. Mesmo que a empresa não esteja crescendo, aprender sobre a gestão implica melhoria dos sistemas de controle gerencial. Aprender exige experiência, experimentação e interação com outras empresas, e é adquirida ao longo do tempo.

Davila (2005) esclarece que tanto a idade quanto o tamanho podem interagir para aumentar a probabilidade do surgimento de SCGs. De acordo com o autor, o aprendizado que acumula com a idade pode não ser relevante para as empresas menores, onde a comunicação e o controle informal podem ser mais eficazes do que SCGs formais. Para empresas menores, os custos de formalização superam seus 
benefícios. Embora a experiência acumulada dessas empresas possa facilitar a implementação de SCG, seu tamanho não requer este procedimento.

Outra característica que pode interferir em diferentes formas de uso dos instrumentos gerenciais é a empresa familiar versus não familiar. Hiebl, Durstmüller e Duller (2013) testaram o impacto do nível de influência da família sobre os aspectos da institucionalização da Contabilidade Gerencial. Os resultados revelaram que as médias empresas, com níveis mais elevados de influência familiar, usam menos instrumentos gerenciais estratégicos e instrumentos de planejamento operacional e apresentam níveis mais baixos de formalização de práticas da Contabilidade Gerencial.

Speckbacher eWentges (2012) observaram que quando os membros da família fazem parte do grupo de executivos de topo, as organizações fazem menor uso de medidas de desempenho, tanto na definição dos objetivos estratégicos, quanto para fornecer incentivos. Tais resultados sinalizam possíveis diferenças na adoção de controles gerenciais entre empresas familiares e não familiares. Na pesquisa realizada por Davila (2005) em empresas de tecnologia, foi constatado que o tamanho e a idade da empresa, a substituição dos CEOs fundadores e a existência de investidores externos promovem o surgimento de sistemas de controle gerencial.

Hiebl, Durstmüller e Duller (2013) aduzem que o estudo de Davila (2005) não mencionou explicitamente a influência familiar, mas que a substituição do CEO fundador e a diluição da participação dos fundadores na empresa por causa da introdução de investidores externos também podem inferir que a influência familiar na empresa é reduzida. Assim, a implementação de um SCG também pode ser parcialmente atribuída à menor influência familiar. Becker, Ulrich e Staffel (2011) encontraram evidências de que as empresas não familiares atuam de forma mais racional e fundamentam as decisões em dados objetivos. Assim, instrumentos estratégicos, como prognósticos e sistemas de informação de gestão, são mais usados em empresas não familiares.

Hiebl, Durstmüller e Duller (2013) mencionam que, à luz da Teoria da Agência, a necessidade de alinhamento de metas oferece uma possível explicação para o maior uso de instrumentos gerenciais estratégicos em empresas com menor influência familiar, uma vez que a propriedade e a gestão estão separadas. Os proprietários tentarão assegurar que os gestores sigam suas visões de longo prazo da empresa, e, assim, instrumentos gerenciais são introduzidos para monitorar o alcance dos objetivos estratégicos (Seal, 2006; Hiebl, Durstmüller \& Duller, 2013).

Pelo até aqui exposto, depreende-se que características das empresas, tanto ambientais como institucionais, influenciam no uso de controles gerenciais. Neste sentido, formulou-se a seguinte hipótese de pesquisa:

H1: As características empresariais (faturamento, regime de tributação, idade, familiar ou não familiar, familiares de primeira geração ou gerações posteriores) implicam diferentes níveis de uso dos controles modernos da Contabilidade Gerencial.

A não rejeição da hipótese $\mathrm{H} 1$ indicará que tamanho, idade da empresa, familiar ou não familiar e geração familiar favorecem o uso de instrumentos modernos da Contabilidade Gerencial. O tamanho e a idade da empresa contribuirão para experimentar novos instrumentos gerenciais, especialmente os modernos. Além disso, com o aumento do tamanho da empresa, aumenta a complexidade das atividades, o que exige a instituição de novos controles. Ainda de acordo com a literatura exposta, as empresas não familiares instituirão maiores controles, visto a necessidade de monitorar a congruência de metas entre gestores e proprietários. 


\subsection{Características dos gestores que afetam o uso de controles gerenciais}

Naranjo-Gil, Maas e Hartmann (2009) mencionam que é, em última instância, o conselho de administração da organização que toma a decisão da adoção de novas práticas da Contabilidade Gerencial e também é o responsável por determinar a extensão do uso de novos sistemas em toda a organização. Consequentemente, os principais gestores são os indivíduos que têm a autoridade de tomada de decisão para adotar novas práticas de gestão (Young, Charns \& Shortell, 2001).

A propensão dos gestores financeiros (Chief Financial Officer-CFOs), controllers e contadores gerenciais apoiar a inovação dos sistemas de controle gerencial varia muito (Naranjo-Gil, Maas \& Hartmann, 2009; Pavlatos, 2010). A partir de pesquisas (Young, Charns \& Shortell, 2001; Naranjo-Gil, Maas \& Hartmann, 2009; Pavlatos, 2010), realizadas em âmbito internacional, especula-se que a idade e a formação educacional de gestores de empresas brasileiras se refletem em diferenças no uso de controles modernos da Contabilidade Gerencial. Parte-se da premissa de que as características demográficas são antecedentes e indicadores de experiências que moldam a base cognitiva de um gestor, que os valores, crenças e habilidades influenciam sua tomada de decisão (Hambrick \& Mason, 1984; Young, Charns \& Shortell, 2001).

Pesquisas teórico-empíricas (Young, Charns \& Shortell, 2001; Naranjo-Gil, Maas \& Hartmann, 2009; Pavlatos, 2010; Pavlatos, 2012) identificaram uma relação negativa entre idade dos gestores e adoção de instrumentos modernos da Contabilidade Gerencial. Pavlatos (2010) menciona que os gestores mais antigos são menos propensos a avaliar rapidamente novas ideias e integrá-las efetivamente na tomada de decisões. Além disso, os CFOs mais antigos têm uma educação contábil mais tradicional e passam a maior parte de sua carreira em uma função tradicional na qual a independência profissional e a contabilidade foram variáveis chave de desempenho (Naranjo-Gil, Maas \& Hartmann, 2009; Pavlatos, 2010).

Young, Charns e Shortell (2001) explicam que com o avanço da idade, os gestores podem se tornar menos flexíveis do ponto de vista cognitivo na adaptação a novas ideias e práticas. Os gestores mais antigos também podem ter investido muito financeiramente e emocionalmente no status quo organizacional e, portanto, não estão dispostos a comprometer-se com grandes empreendimentos. Os gestores mais jovens e com maior formação educacional estão mais inclinados a se envolver em iniciativas de mudança e implementar inovações. Podem ainda ter menos compromisso emocional com uma maneira particular de gerenciar e, portanto, são mais receptivos a novas ideias (Young, Charns \& Shortell, 2011).

A formação acadêmica do gestor, de acordo com Oliveira, Mueller e Nakamura (2000), influencia no uso correto de informações geradas pelos Sistemas de Informação Gerencial. Os autores observaram que profissionais com formação acadêmica na área de Ciências Sociais Aplicadas utilizam com maior intensidade informações geradas pelo sistema, portanto, observaram uma associação entre as variáveis formação acadêmica e grau de uso.

Hambrick e Mason (1984) preconizam que o conhecimento educacional formal de uma pessoa pode render informações ricas e complexas. Até certo ponto, a educação indica o conhecimento e a habilidade de uma pessoa. Para os autores, uma pessoa formada em engenharia tende a ter uma base cognitiva diferente de alguém formado em história ou em leis. Além disso, se assumir que a maioria das pessoas leva a sério sua decisão sobre educação, então a educação serve até certo ponto como indicador dos valores de uma pessoa e preferências cognitivas.

A partir da premissa de que os antecedentes educacionais dos gestores afetam seus processos de decisão (Hambrick \& Mason, 1984), Naranjo-Gil, Maas e Hartmann (2009) aduzem que CFOs com formação na área de negócios são mais receptivos às pressões para usar instrumentos modernos da Contabilidade 
Gerencial, pois o seu conhecimento lhes deixa mais receptivos às soluções que os sistemas oferecem. Além disso, são mais familiarizados com os instrumentos gerenciais e mais abertos às mudanças de sistemas do que os CFOs, cuja experiência contém um histórico operacional dominante.

A partir do exposto, elaborou-se a seguinte hipótese de pesquisa:

H2: Há diferenças no uso dos controles gerenciais modernos nas empresas conforme o perfil dos gestores (idade, escolaridade e formação).

A não rejeição da hipótese $\mathrm{H} 2$ indicará que dados demográficos (idade, escolaridade, formação na área de negócios) dos gestores podem ser preditores do uso de instrumentos gerenciais nas organizações, condizente com a literatura dos escalões superiores preconizada por Hambrick e Mason (1984).

\section{MÉTODO E PROCEDIMENTOS DA PESQUISA}

\subsection{População e amostra}

A população deste estudo compreendeu as 939 empresas industriais de uma cidade da região Sul do Brasil, listadas no cadastro geral da Prefeitura Municipal. Da população, foram excluídos 57 microempreendedores individuais, permanecendo 882 empresas. Ainda foram excluídas 349 microempresas, por tratarem-se de organizações muito pequenas conforme cadastro da prefeitura, em que é pouco provável o uso de instrumentos gerenciais modernos, permanecendo 533.

Das 533 empresas ainda excluíram-se 360 empresas cadastradas na prefeitura como empresa de pequeno porte (EPP). Optou-se pela exclusão dessas pelo fato de acreditar-se que diversos instrumentos gerenciais não estariam em uso, visto que a maioria refere-se a confecções de peças do vestuário (272), além de padarias, confeitarias, sorveterias, marcenarias, entre outros. Além disso, foram excluídas mais 11 empresas cuja situação cadastral consta como baixada. Após as exclusões obteve-se uma população ajustada de 162 empresas.

O cadastro geral fornecido pela prefeitura estava incompleto em relação a algumas informações importantes para a pesquisa, como telefone e e-mail de contato. Esse cadastramento foi realizado em duas etapas: a) busca do telefone de contato das empresas em dois locais, na lista telefônica e nos sites de busca; b) cadastro dos e-mails de contato das empresas. Alguns e-mails foram localizados na web site das empresas, e os demais foram identificados por contato telefônico.

Após o envio do questionário via Google Docs, obteve-se a resposta de 37 empresas industriais, o que corresponde a $22,84 \%$ do total da população ajustada. A maioria dos participantes é de indústrias metalúrgicas, de máquinas e equipamentos, de plásticos e madeireiras. Dos respondentes, 24 são optantes do Simples Nacional e 10 do lucro real. Quanto ao faturamento anual, 16 empresas informaram faturamento até $\mathrm{R} \$ 500$ mil reais, nove até 1 milhão e 12 acima de 1 milhão de reais. Quanto a idade das empresas, 16 possuem mais de 20 anos, enquanto que 8 têm entre 11 e 20 anos e 13 delas entre 1 e 10 anos.

Quanto às características familiares, das 37 empresas participantes da pesquisa, 25 reportaram que são familiares. Esta classificação foi na percepção dos respondentes, no entendimento que possuem sobre características familiares de suas empresas. Das 25 empresas que consideram-se familiares, a maioria (14) ainda está na primeira geração. No entanto, oito já passaram por um processo sucessório e uma já se encontra na quarta geração. Duas empresas, apesar de considerarem-se familiares, não indicaram a geração familiar que está no comando. 
Os respondentes do questionário, em sua maioria, exercem a função de administrador $(37,84 \%)$ ou de diretor $(32,43 \%)$ nas empresas pesquisadas. Quanto à idade, houve maior concentração de respondentes nas faixas de 18 a 30 anos ( 14 respondentes) e 41 a 50 anos (12 respondentes), o que demonstra certo equilíbrio entre respondentes mais jovens e mais experientes. Além disso, mais da metade dos respondentes possuem graduação (27), sendo que desses, 10 possuem um curso de pós-graduação (especialização). As áreas de formação acadêmica concentraram-se mais em Ciências Contábeis, Administração e Gestão Financeira.

\subsection{Instrumento da pesquisa}

O instrumento de pesquisa foi composto de três partes principais, com o intuito de averiguar o uso dos controles gerenciais tradicionais e modernos da Contabilidade Gerencial pelas empresas, além de identificar as características das empresas e dos gestores (perfil dos respondentes).

Para capturar o uso dos controles gerenciais, foram expostas assertivas englobando 20 instrumentos, sendo 10 tradicionais e 10 modernos, em que foi solicitado aos respondentes indicar seu grau de concordância em relação ao uso destes instrumentos, numa escala Likert de cinco pontos, variando de discordo totalmente a concordo totalmente. Estas 20 assertivas foram retiradas dos estudos de Soutes (2006), Correia (2010) e Valeriano (2012), visto que eles apresentaram um glossário de cada controle gerencial. Os instrumentos pesquisados, suas respectivas assertivas e autores podem ser visualizados na Figura 1.

Figura 1: Construto para capturar o uso de instrumentos gerenciais

\begin{tabular}{|c|c|c|}
\hline Instrumentos & Assertivas & Autores \\
\hline Benchmarking* & $\begin{array}{l}\text { A sua empresa, sistematicamente, realiza comparação dos processos e dos resultados } \\
\text { (preços, por exemplo) com empresas do mesmo setor de atividade, buscando criar } \\
\text { novos padröes e/ou melhorar o resultado da empresa. }\end{array}$ & \multirow{3}{*}{ Valeriano (2012) } \\
\hline Balanced scorecard* & $\begin{array}{l}\text { A sua empresa monitora a execução da estratégia de forma balanceada, utilizando } \\
\text { indicadores de desempenho - financeiros e não financeiros - com base em quatro } \\
\text { perspectivas: financeira, cliente, processos internos e aprendizado e crescimento. }\end{array}$ & \\
\hline Custeio $\mathrm{ABC}^{*}$ & $\begin{array}{l}\text { A sua empresa gerencia os custos por meio de atividades, encontrando bases que } \\
\text { representam as relaçôes entre os custos das atividades e os objetivos dos custos, } \\
\text { como produtos, processos e ordens, pois compreende que atividades consomem } \\
\text { os recursos e os bens e serviços consomem atividades. }\end{array}$ & \\
\hline $\begin{array}{l}\text { Custeio do ciclo de vida do } \\
\text { produto* }\end{array}$ & $\begin{array}{l}\text { A mensuração dos custos é realizada em todas as fases do produto: concepção } \\
\text { do projeto, desenvolvimento, produção, entrega ao consumidor e o pós venda. }\end{array}$ & Correia (2010) \\
\hline Custeio por absorção & $\begin{array}{l}\text { A sua empresa, quando apura o custo da mercadoria produzida, soma os custos } \\
\text { diretos e indiretos, fixos e variáveis incorridos no período de apuração. }\end{array}$ & \multirow{3}{*}{ Valeriano (2012) } \\
\hline Custeio variável & $\begin{array}{l}\text { A sua empresa, quando apura o custo da mercadoria produzida, soma apenas os } \\
\text { custos variáveis (matéria-prima, por exemplo) incorridos no período de apuração. }\end{array}$ & \\
\hline Custo padrão & $\begin{array}{l}\text { A sua empresa possui um padrão de comportamento para os custos, ou seja, fixa } \\
\text { quais são os montantes esperados no final do período de apuração e compara } \\
\text { com os custos reais. }\end{array}$ & \\
\hline Descentralização & $\begin{array}{c}\text { A empresa calcula rentabilidade por cliente, canal de distribuição, região, entre } \\
\text { outros. }\end{array}$ & Soutes (2006) \\
\hline DFC & $\begin{array}{l}\text { A sua empresa utiliza o demonstrativo de fluxo de caixa e/ou o fluxo de caixa } \\
\text { projetado no processo decisório. }\end{array}$ & \multirow[b]{2}{*}{ Valeriano (2012) } \\
\hline $\mathrm{EVA}^{\oplus *}$ & $\begin{array}{l}\text { A sua empresa utiliza a medida de desempenho, tendo por base o lucro residual } \\
\text { (lucro operacional líquido reduzido do custo do capital - custo de oportunidade) } \\
\text { nos moldes do instrumento EVA. }\end{array}$ & \\
\hline Just in time* & $\begin{array}{l}\text { A sua empresa aplica a filosofia de produção na quantidade certa, no momento } \\
\text { certo, com a quantidade adequada, sem formação de estoque e sem desperdício, } \\
\text { aplicando o programa de melhoria contínua nos moldes do just in time. }\end{array}$ & Correia (2010) \\
\hline Kaizen* & $\begin{array}{l}\text { A empresa pratica a melhoria contínua dos produtos, processos, empregados } \\
\text { entre outros. }\end{array}$ & Soutes (2006) \\
\hline Orçamento & $\begin{array}{l}\text { Anualmente é elaborado um plano formal para expressar quantitativamente o plano } \\
\text { de ação da organizaçãa. Desta forma, a empresa tem elaborado para o ano seguinte, } \\
\text { o orçamento de vendas, de produção, de compras, de despesas, de investimentos, de } \\
\text { caixa, projetando a demonstração de resultado e o balanço patrimonial. }\end{array}$ & \multirow{3}{*}{ Correia (2010) } \\
\hline Planejamento estratégico* & $\begin{array}{l}\text { Tem-se como prática a elaboração de um instrumento formal, de longo prazo, no } \\
\text { qual se apresentam a missão, a visãa e as estratégias organizacionais, estabelecendo } \\
\text { os objetivos e as políticas, verificando as ameaças e as oportunidades, os pontos } \\
\text { fortes e os pontos fracos e direcionando os rumos da organização. }\end{array}$ & \\
\hline Planejamento tributário & $\begin{array}{l}\text { A sua empresa utiliza mecanismos de gestão de tributos com a finalidade de analisar } \\
\text { a melhor opção tributária a ser aplicada, visando a redução do pagamento de } \\
\text { tributos, observando sempre os preceitos legais. }\end{array}$ & \\
\hline
\end{tabular}




\begin{tabular}{|c|c|c|}
\hline Preço de transferência & $\begin{array}{l}\text { Para efeitos gerenciais a empresa utiliza o Preço de Transferência baseado em custos } \\
\text { ou preços de mercado. }\end{array}$ & Soutes (2006) \\
\hline Retorno sobre o investimento & $\begin{array}{c}\text { É pratica de a empresa medir o seu desempenho utilizando a relação entre o lucro } \\
\text { e o investimento. Utilizam índices econômico-financeiros tais como ROI, Retorno } \\
\text { sobre PL, índices de liquidez entre outros. }\end{array}$ & Correia (2010); Soutes (2006) \\
\hline Simulação* & São realizadas simulações de rentabilidade dos produtos (Receitas, custos e margem). & \multirow{2}{*}{ Soutes (2006) } \\
\hline Teoria das restrições* & A empresa avalia a margem de contribuição por fator limitante de produção. & \\
\hline Valor presente & $\begin{array}{l}\text { A sua empresa, quando realiza investimentos de longo prazo, costuma levar em } \\
\text { consideração que o dinheiro tem valor ao longo do tempo e calcula quanto os } \\
\text { futuros pagamentos somados a um custo inicial estariam valendo atualmente. }\end{array}$ & Valeriano (2012) \\
\hline
\end{tabular}

Nota: *Instrumentos modernos da Contabilidade Gerencial

Fonte: Elaboração própria

\subsection{Procedimentos de análise dos dados}

$\mathrm{Na}$ análise dos dados foram utilizadas técnicas de estatística descritiva, correlações de Spearman e testes não paramétricos de Mann-Whitney U e Kruskal-Wallis. Na estatística descritiva foram determinados a média, desvio padrão e coeficiente de variação, além de quantificar as respostas de acordo com a escala Likert para discorrer sobre o uso dos controles gerenciais tradicionais e modernos pelas empresas investigadas. A técnica de correlação de Spearman foi aplicada para verificar a força do relacionamento entre os controles tradicionais e modernos com as características das empresas e dos gestores. Analisou-se a associação por tipos de controles e por grupos (tradicionais e modernos) com as características.

Para testar as hipóteses da pesquisa comparou-se o uso dos controles gerenciais com características das empresas e dos gestores. Para isso, utilizaram-se testes não paramétricos de Mann-Whitney U e Kruskal-Wallis, já que os testes Kolmogorov-Smirnov e Shapiro-Wilk indicaram que os dados não apresentam distribuição normal $(s i g<0,05)$. $O$ teste de Mann-Whitney $U$ foi utilizado como alternativa ao teste-t de duas amostras para médias, enquanto que o teste de Kruskal-Wallis foi utilizado para testar se três ou mais amostras independentes foram extraídas de populações com médias iguais (Fávero, Belfiore, Silva \& Chan, 2009).

\section{DESCRIÇÃO E ANÁLISE DOS DADOS}

\subsection{Uso dos controles gerenciais pelas empresas pesquisadas}

Na Tabela 1, evidencia-se estatísticas descritivas (média, desvio padrão e coeficiente de variação) relativas ao uso dos controles gerenciais nas empresas pesquisadas, além da quantidade de empresas que assinalaram as opções usa pouco (escala 1 e 2 - não usa e usa pouco), uso razoável (escala 3) e usa muito (escala 5 e 4 - usa bastante e usa muito).

Tabela 1: Estatísticas descritivas do uso de controles gerenciais

\begin{tabular}{|c|c|c|c|c|c|c|c|}
\hline Instrumento Gerencial & Classificação & Média & D. Padrão & Coef. Variação & Usa pouco & Uso razoável & Usa muito \\
\hline Balanced scorecard & M & 3,16 & 1,34 & $42,5 \%$ & 16 & 4 & 17 \\
\hline Benchmarking & M & 4,14 & 1,08 & $26,2 \%$ & 5 & 4 & 28 \\
\hline Ciclo de vida do produto & M & 3,38 & 1,32 & $39,1 \%$ & 10 & 8 & 19 \\
\hline Custeio ABC & M & 2,78 & 1,53 & $55,0 \%$ & 17 & 5 & 15 \\
\hline Custo padrão & T & 3,46 & 1,30 & $37,7 \%$ & 8 & 7 & 22 \\
\hline Custeio por absorção & T & 4,03 & 1,21 & $30,1 \%$ & 5 & 5 & 27 \\
\hline Custeio variável & T & 2,24 & 1,42 & $63,4 \%$ & 21 & 6 & 10 \\
\hline Descentralização & T & 2,62 & 1,44 & $54,9 \%$ & 20 & 5 & 12 \\
\hline DFC & T & 2,86 & 1,44 & $50,2 \%$ & 18 & 4 & 15 \\
\hline EVA & M & 2,03 & 1,12 & $55,1 \%$ & 24 & 8 & 5 \\
\hline
\end{tabular}




\begin{tabular}{|c|c|c|c|c|c|c|c|}
\hline Just in time & M & 2,70 & 1,43 & $53,0 \%$ & 16 & 8 & 13 \\
\hline Kaizen & M & 3,57 & 1,32 & $37,1 \%$ & 9 & 4 & 24 \\
\hline Orçamento & T & 2,70 & 1,29 & $47,7 \%$ & 17 & 10 & 10 \\
\hline Planejamento estratégico & M & 2,62 & 1,36 & $51,9 \%$ & 20 & 7 & 10 \\
\hline Planejamento tributário & T & 3,51 & 1,15 & $32,6 \%$ & 7 & 10 & 20 \\
\hline Preço de transferência & T & 2,51 & 1,43 & $56,7 \%$ & 19 & 6 & 12 \\
\hline Retorno sobre o investimento & T & 3,00 & 1,03 & $34,2 \%$ & 11 & 14 & 12 \\
\hline Simulação & M & 3,57 & 1,09 & $30,7 \%$ & 6 & 9 & 22 \\
\hline Teoria das restrições & M & 2,41 & 1,34 & $55,8 \%$ & 17 & 13 & 7 \\
\hline Valor presente & T & 3,24 & 1,55 & $47,9 \%$ & 13 & 5 & 19 \\
\hline
\end{tabular}

As estatísticas descritivas apresentadas na Tabela 1 mostram que a intensidade de uso dos controles gerenciais é heterogênea, com exceção, de alguns instrumentos, como, benchmarking, custeio por absorção, simulação e planejamento tributário, que apresentaram menor variabilidade nas respostas. Dentre os instrumentos considerados tradicionais da Contabilidade Gerencial, verifica-se maior uso do custeio por absorção, planejamento tributário e custo padrão.

Nos instrumentos modernos, destacam-se o benchmarking, simulação, kaizen e ciclo de vida do produto. Esse resultado converge com o de Hyvönen (2005) e Soutes (2006), que encontraram, respectivamente, uso de $88 \%$ e $85 \%$ do benchmarking nas empresas analisadas em suas pesquisas. Em relação à simulação, resultados semelhantes foram encontrados por Sulaiman, Ahmad e Alwi (2004), em que o uso da simulação de rentabilidade era superior a 55\% nas empresas asiáticas analisadas. Entretanto, os resultados encontrados para kaizen destoam de pesquisas nacionais, como de Teixeira et al. (2011), Oyadomari et al. (2008) e Reis e Teixeira (2013), em que apresentou-se entre os menos usados. O instrumento de pesquisa pode ser responsável por tal divergência, uma vez que neste estudo apresentou-se o conceito de cada controle aos respondentes, o que pode levar a entendimento distinto por parte dos gestores.

Os instrumentos de menor uso indicados pelas empresas são o EVA ${ }^{\oplus}$, custeio variável, teoria das restrições, preço de transferência, descentralização e planejamento estratégico. Reginato e Guerreiro (2011) também identificaram baixo uso do $\mathrm{EVA}^{\oplus}$ e da Teoria da Restrições nas empresas que pesquisaram. $\mathrm{O}$ baixo uso do $\mathrm{EVA}^{\oplus}$ sugere que as empresas adotam outros instrumentos para análise do desempenho, como o benchmarking. De acordo com Reginato e Guerreiro (2011), o benchmarking se constitui em uma forma usual de mensuração e avaliação de desempenho por ser uma prática de contínua comparação dos produtos, serviços e modelos de gestão entre as empresas e os seus concorrentes, o que permite a criação de padrões ou melhoria de processos.

Dentre os métodos de custeio, sobressai-se o uso do custeio por absorção, seguido o custeio padrão. Tanto o custeio baseado em atividades como o custeio variável não são utilizados pela maioria das organizações pesquisadas. Este resultado conflui com as pesquisas de Frezatti (2005), Guerreiro, Cornacchione Jr e Soutes (2011) e Reis e Teixeira (2013), que também encontraram elevados níveis de uso do custeio absorção pelas empresas que investigaram. Tal é justificável pelo fato da amostra ser composta de empresas industriais, que são obrigadas a apurar o inventário e escriturar a movimentação da produção, além de que o custeio por absorção é o único método de custeio aceito pelo fisco. No entanto, diverge dos estudos de Oyadomari et al. (2008) e Reis e Teixeira (2013), em que o custeio variável apresentou-se como um dos controles gerenciais mais usados pelas empresas investigadas. Isso sinaliza que a maioria das empresas pesquisadas não segregam os custos entre fixos e variáveis para a tomada de decisão, e 
sim, apenas seguem os preceitos contábeis vigentes. Porém, muitas utilizam o custo do ciclo de vida do produto e o custo padrão como instrumento de controle de produção.

Quanto aos métodos de mensuração e avaliação de medidas de desempenho, conforme classificação adotada por Soutes (2006), percebe-se maior ênfase no benchmarking, valor presente e retorno sobre o investimento. Esses resultados convergem parcialmente com os de Soutes (2006), em que o valor presente obteve uso de $52 \%$ por empresas de médio e grande porte. Porém, enquanto na pesquisa da autora a descentralização e o orçamento apresentaram altos níveis de uso, 72\% e 53\% respectivamente, nesta pesquisa as médias destes controles não chegaram a atingir o ponto central da escala.

A maioria das filosofias e modelos de gestão não é utilizada com muita intensidade. Ao fazer uma analogia com os estágios da Contabilidade Gerencial, percebe-se maior preocupação das empresas com a determinação do custo e controle financeiro, além, do planejamento tributário. Chama a atenção ainda que o planejamento estratégico e o orçamento não se constituem em práticas institucionalizadas na maioria das empresas pesquisadas. De acordo com Otley (1999), o orçamento tem sido tradicionalmente um mecanismo de controle usado na maioria das empresas, por integrar toda a gama de atividades organizacionais.

De modo geral, as estatísticas descritivas mostram que o uso dos controles tradicionais não se sobressai aos controles modernos, sendo que a variação (maior ou menor uso) se dá por tipo de instrumento e a sua finalidade (apuração de custos, apoio à tomada de decisão, filosofias de gestão, avaliação de desempenho), o que sinaliza que ambos os tipos estão presentes ou ausentes nas empresas. Tais resultados divergem de Frezatti (2005), que constatou maior uso dos controles gerenciais modernos. Já Teixeira et al. (2011) constataram que as empresas do estado do Espírito Santo utilizam tanto controles tradicionais como modernos.

\subsection{Associação do uso de controles gerenciais com características das empresas e dos}

gestores

Na Tabela 2, evidencia-se as correlações de Spearman de instrumentos da Contabilidade Gerencial com características das empresas e dos gestores.

Tabela 2: Associação do uso de controles gerenciais com características das empresas e dos gestores

\begin{tabular}{|c|c|c|c|c|c|c|c|c|c|}
\hline Instrumento Gerencial & Classif & $\begin{array}{c}\text { Fatura } \\
\text { mento }\end{array}$ & $\begin{array}{c}\text { Tribu } \\
\text { taçăo }\end{array}$ & Idade Empresa & Familiar & $\begin{array}{c}\text { Geracãa } \\
\text { Familiar }\end{array}$ & $\begin{array}{c}\text { Idade } \\
\text { Gestor }\end{array}$ & $\begin{array}{c}\text { Escola } \\
\text { ridade }\end{array}$ & $\begin{array}{c}\text { Tipo de } \\
\text { Formaçăo }\end{array}$ \\
\hline Balanced scorecard & $\mathrm{M}$ & 0,220 & 0,168 & $-0,163$ & $0,350^{*}$ & 0,063 & $-0,487^{* *}$ & $0,387^{*}$ & 0,320 \\
\hline Benchmarking & $\mathrm{M}$ & 0,241 & 0,035 & $-0,237$ & $-0,488^{* *}$ & $-0,602^{* *}$ & 0,116 & $-0,102$ & $-0,347^{*}$ \\
\hline $\begin{array}{c}\text { Ciclo de vida do } \\
\text { produto }\end{array}$ & $\mathrm{M}$ & 0,129 & 0,228 & $-0,307$ & 0,053 & $-0,137$ & $-0,464^{* *}$ & $0,435^{* *}$ & 0,205 \\
\hline Custeio ABC & $\mathrm{M}$ & 0,025 & 0,221 & $-0,138$ & $0,518^{* *}$ & $0,337^{*}$ & $-0,663^{* *}$ & $0,349^{*}$ & $0,357^{*}$ \\
\hline Custo padrão & $\mathrm{T}$ & 0,093 & 0,127 & $-0,414^{*}$ & $-0,286$ & $-0,334^{*}$ & 0,162 & 0,124 & $-0,187$ \\
\hline Custeio por absorção & $\mathrm{T}$ & 0,043 & $-0,094$ & $-0,065$ & $-0,308$ & $-0,298$ & $-0,009$ & 0,024 & $-0,090$ \\
\hline Custeio variável & $\mathrm{T}$ & $-0,299$ & $-0,092$ & $-0,242$ & 0,185 & 0,095 & $-0,004$ & $-0,028$ & $-0,099$ \\
\hline Descentralização & $\mathrm{T}$ & 0,011 & $0,397^{*}$ & $-0,168$ & $0,383^{*}$ & 0,066 & $-0,158$ & 0,234 & 0,109 \\
\hline DFC & $\mathrm{T}$ & 0,030 & 0,196 & $-0,200$ & $0,435^{* *}$ & 0,255 & $-0,313$ & $0,371^{*}$ & 0,275 \\
\hline EVA & $\mathrm{M}$ & $-0,239$ & 0,093 & $-0,011$ & $0,621^{* *}$ & $0,428^{* *}$ & $-0,303$ & 0,270 & 0,275 \\
\hline Just in time & $\mathrm{M}$ & 0,008 & 0,232 & $-0,130$ & $0,474^{* *}$ & 0,285 & $-0,381^{*}$ & 0,212 & 0,170 \\
\hline Kaizen & $\mathrm{M}$ & $-0,034$ & 0,099 & $-0,157$ & 0,194 & 0,109 & $-0,271$ & 0,107 & 0,229 \\
\hline Orçamento & $\mathrm{T}$ & 0,272 & $0,459^{* *}$ & $-0,135$ & 0,164 & 0,070 & $-0,274$ & $0,488^{* *}$ & 0,151 \\
\hline $\begin{array}{c}\text { Planejamento } \\
\text { estratégico }\end{array}$ & $\mathrm{M}$ & 0,071 & 0,180 & $-0,172$ & $0,328^{*}$ & 0,240 & $-0,578^{* *}$ & $0,498^{* *}$ & $0,328^{*}$ \\
\hline
\end{tabular}




\begin{tabular}{|c|c|c|c|c|c|c|c|c|c|}
\hline $\begin{array}{c}\text { Planejamento } \\
\text { tributário }\end{array}$ & $\mathrm{T}$ & $0,354^{*}$ & $0,354^{*}$ & $-0,240$ & 0,039 & $-0,006$ & $-0,356^{*}$ & 0,257 & 0,291 \\
\hline Preço de transferência & $\mathrm{T}$ & $-0,199$ & 0,130 & $-0,152$ & $0,565^{* *}$ & $0,447^{* *}$ & $-0,357^{*}$ & 0,169 & 0,258 \\
\hline $\begin{array}{c}\text { Retorno sobre o } \\
\text { investimento }\end{array}$ & $\mathrm{T}$ & $-0,070$ & 0,310 & $-0,341^{*}$ & 0,232 & 0,064 & $-0,187$ & $0,488^{* *}$ & 0,140 \\
\hline Simulação & $\mathrm{M}$ & 0,006 & $-0,078$ & 0,178 & $-0,102$ & $-0,029$ & $-0,333^{*}$ & 0,099 & 0,247 \\
\hline Teoria das restrições & $\mathrm{M}$ & $-0,163$ & 0,101 & $-0,208$ & $0,413^{*}$ & 0,172 & $-0,250$ & 0,175 & 0,083 \\
\hline Valor presente & $\mathrm{T}$ & 0,148 & 0,212 & 0,094 & 0,092 & $-0,079$ & $-0,247$ & 0,173 & $-0,070$ \\
\hline Tradicionais em geral & $\mathrm{T}$ & 0,060 & $0,406^{*}$ & $-0,347^{*}$ & 0,284 & 0,033 & $-0,299$ & $0,425^{* *}$ & 0,167 \\
\hline Modernos em geral & $\mathrm{M}$ & 0,028 & 0,210 & $-0,206$ & $\mathbf{0 , 4 1 1 ^ { * }}$ & 0,156 & $-0,578^{* *}$ & $0,394^{*}$ & $0,330^{*}$ \\
\hline
\end{tabular}

Nota: A correlação é significativa *ao nível de 0,05 (2 extremidades) ou **ao nível de 0,01 (2 extremidades)

De maneira geral, na Tabela 2 evidencia-se que o uso dos controles modernos da Contabilidade Gerencial está associado positivamente com a escolaridade dos gestores e o tipo de formação acadêmica e negativamente com a idade dos gestores. Portanto, gestores com maior grau de escolaridade (graduação, especialização) tendem a utilizar mais os controles modernos da Contabilidade Gerencial, como, balanced scorecard, ciclo de vida do produto, custeio ABC, planejamento estratégico, comparativamente aos gestores sem ensino superior.

Associação positiva também é observada na comparação do tipo de formação (contabilidade/administração/finanças versus outros) com o uso do custeio $A B C$, planejamento estratégico e instrumentos modernos analisados, de modo geral. A escolaridade também está associada com o uso de instrumentos tradicionais da Contabilidade Gerencial, como, DFC, orçamento, retorno sobre o investimento.

A idade do gestor apresenta associação negativa com a maioria dos instrumentos modernos da Contabilidade Gerencial. Gestores mais velhos tendem a ser mais tradicionais e não incorporam as novas práticas no cotidiano de seu trabalho, conforme preconizado por Young, Charns e Shortell (2001), Naranjo-Gil, Maas e Hartmann (2009) e Pavlatos (2010). De acordo com Naranjo-Gil, Maas e Hartmann (2009), gestores que gastaram parte substancial de sua carreira em uma organização provavelmente desenvolverão uma base de poder, redes sociais e rotinas de trabalho que não querem colocar em risco, mesmo que acreditem que a inovação e a mudança seriam de interesse da organização.

Por outro lado, gestores mais jovens ingressaram na profissão mais recentemente e, portanto, tendem a se familiarizar com os ambientes contemporâneos da Contabilidade Gerencial durante sua educação (Pavlatos, 2010). Young, Charns e Shortell (2001) explicam que os gestores mais jovens são mais receptivos a novas ideias e, geralmente, possuem menos compromisso emocional com algum modo específico de gerenciar, o que pode explicar a associação negativa entre os controles modernos e a idade do gestor.

Em relação às características das empresas, apenas faturamento apresentou correlação positiva e significativa com planejamento tributário. A forma de tributação apresentou associação com descentralização, orçamento, planejamento tributário e instrumentos tradicionais da Contabilidade Gerencial. Decorre que empresas do lucro real realizam constantemente algum tipo de planejamento tributário, como, por exemplo, a escolha do lucro real anual ou trimestral. Para tal, pode-se fazer uso de alguns instrumentos gerenciais, por exemplo, o orçamento.

A associação do uso de instrumentos gerenciais com a característica de empresa familiar diverge, nesta pesquisa, do entendimento de uma corrente da literatura que utiliza preceitos da Teoria da Agência e da Teoria Stewarship para explicar que as empresas familiares utilizam menos instrumentos de controle do que as não familiares (Speckbacher \& Wentges, 2012; Hiebl, Durstmüller \& Duller, 2013; Helsen, Lybaert, Steijvers, Orens \& Dekker, 2017). A tomada de decisão nestas empresas é centrada em familiares, que decidem quais instrumentos implementar, e essa escolha depende de características 
como idade e formação acadêmica (Young, Charns \& Shortell, 2001). Hiebl, Durstmüller e Duller (2013) advertem que a institucionalização de práticas de controle gerencial em empresas familiares depende dos níveis de educação dos membros da família envolvidos na gestão.

No contexto específico das empresas familiares, as práticas de Contabilidade Gerencial podem ser formalizadas para reproduzir o conhecimento do fundador da empresa, atuando como uma linguagem comum, capaz de transferir conhecimento entre os diferentes grupos de indivíduos que se envolvem nessas práticas (Giovannoni, Maraghini \& Riccaboni, 2011). Assim, de maneira geral, os resultados desta pesquisa sugerem que o uso dos instrumentos gerenciais está associado principalmente com as características dos gestores das empresas pesquisadas, em detrimento das próprias características das empresas.

Chua, Chrisman e Bergiel (2009) mencionam que empresas familiares tendem a adotar uma orientação de longo prazo, visando manter o negócio nas mãos da família. Desse modo, a sucessão de negócios e uma orientação de longo prazo se tornam metas importantes para empresas familiares, por conseguinte, atribuem menor valor a relatórios de resultados e variações de desempenho de curto prazo (Chrisman, Chua \& Sharma, 2005; Hiebel, 2012). Portanto, as empresas familiares dependem menos de controles de gestão de curto prazo, orientados para ênfase interna e financeira, pois dependem mais de instrumentos estratégicos que possam promover o bem-estar no longo prazo da empresa familiar (Hiebel, 2012). Isso explica a associação com vários controles modernos, visto que estes possuem uma orientação de longo prazo (Chenhall \& Langfield-Smith,1998).

Giovannoni, Maraghini e Riccaboni (2011) destacam que, os membros da família podem direcionar a institucionalização de controles gerenciais para facilitar a sucessão ou a transição para um negócio não familiar. $O$ uso de controles gerenciais em empresas familiares também pode ser explicado a partir do ciclo de vida organizacional (Helsen et al. 2017), de que as empresas, inclusive as familiares, adotam mecanismos de controles formais para lidar com o aumento da complexidade à medida que evoluem $\mathrm{e}$ crescem. Para Giovannoni, Maraghini e Riccaboni (2011), a Contabilidade Gerencial pode desempenhar papel relevante na gestão da incerteza durante os processos de profissionalização e sucessão ao longo do ciclo de vida de empresas familiares.

\subsection{Uso de controles gerenciais e características das empresas e dos gestores}

Na Tabela 3, faz-se um comparativo entre grupos de acordo com as características das empresas (faturamento, regime de tributação, idade, familiar ou não familiar, familiares de primeira geração ou gerações posteriores) e dos gestores (escolaridade, formação acadêmica e idade). $O$ teste Mann-Whitney foi aplicado para comparações entre dois grupos, e o Kruskal-Wallis para comparar três grupos.

Tabela 3: Características das empresas e dos gestores e uso de controles gerenciais

\begin{tabular}{|c|c|c|c|c|c|c|c|c|c|}
\hline Controles & T/M & Faturamento & $\begin{array}{c}\text { Regime } \\
\text { Tributação }\end{array}$ & Idade Empresa & $\begin{array}{c}\text { Empresa } \\
\text { Familiar }\end{array}$ & $\begin{array}{c}\text { Geração } \\
\text { Familiar }\end{array}$ & Escolaridade & Formação & $\begin{array}{c}\text { Idade } \\
\text { Gestor }\end{array}$ \\
\hline $\begin{array}{c}\text { Balanced } \\
\text { scorecard }\end{array}$ & M & 0,138 & 0,337 & 0,593 & 0,041 & 0,221 & 0,023 & 0,066 & 0,012 \\
\hline $\begin{array}{c}\text { Benchmarking } \\
\text { Ciclo de vida do } \\
\text { produto }\end{array}$ & M & 0,129 & 0,863 & 0,212 & 0,006 & 0,001 & 0,578 & 0,057 & 0,799 \\
\hline Custeio ABC & M & 0,769 & 0,189 & 0,256 & 0,761 & 0,426 & 0,009 & 0,233 & 0,029 \\
\hline $\begin{array}{c}\text { Custeio } \\
\text { absorção }\end{array}$ & T & 0,077 & 0,200 & 0,696 & 0,002 & 0,081 & 0,040 & 0,036 & 0,000 \\
\hline Custeio variável & T & 0,293 & 0,604 & 0,876 & 0,089 & 0,199 & 0,906 & 0,620 & 0,685 \\
\hline Custo padrão & T & 0,814 & 0,479 & 0,075 & 0,102 & 0,064 & 0,489 & 0,284 & 0,799 \\
\hline
\end{tabular}




\begin{tabular}{|c|c|c|c|c|c|c|c|c|c|}
\hline $\begin{array}{c}\text { Demonstração } \\
\text { dos Fluxos de } \\
\text { Caixa }\end{array}$ & $\mathrm{T}$ & 0,503 & 0,263 & 0,147 & 0,009 & 0,050 & 0,028 & 0,111 & 0,150 \\
\hline Descentralização & $\mathrm{T}$ & 0,260 & 0,020 & 0,135 & 0,025 & 0,006 & 0,180 & 0,538 & 0,578 \\
\hline $\mathrm{EVA}^{\oplus}$ & M & 0,096 & 0,604 & 0,443 & 0,000 & 0,022 & 0,130 & 0,126 & 0,233 \\
\hline Just in time & M & 0,279 & 0,179 & 0,872 & 0,005 & 0,038 & 0,229 & 0,327 & 0,081 \\
\hline Kaizen & M & 0,038 & 0,582 & 0,426 & 0,267 & 0,202 & 0,555 & 0,189 & 0,134 \\
\hline Orçamento & $\mathrm{T}$ & 0,242 & 0,006 & 0,563 & 0,344 & 0,673 & 0,003 & 0,391 & 0,169 \\
\hline $\begin{array}{l}\text { Planejamento } \\
\text { estratégico }\end{array}$ & M & 0,480 & 0,306 & 0,608 & 0,057 & 0,347 & 0,003 & 0,050 & 0,003 \\
\hline $\begin{array}{l}\text { Planejamento } \\
\text { tributário }\end{array}$ & $\mathrm{T}$ & 0,004 & 0,039 & 0,079 & 0,835 & 0,763 & 0,139 & 0,092 & 0,066 \\
\hline $\begin{array}{c}\text { Preço de } \\
\text { transferência }\end{array}$ & $\mathrm{T}$ & 0,045 & 0,460 & 0,417 & 0,001 & 0,018 & 0,335 & 0,142 & 0,111 \\
\hline $\begin{array}{l}\text { Retorno sobre o } \\
\text { investimento }\end{array}$ & $\mathrm{T}$ & 0,950 & 0,077 & 0,138 & 0,192 & 0,062 & 0,004 & 0,425 & 0,271 \\
\hline Simulação & M & 0,880 & 0,672 & 0,051 & 0,575 & 0,965 & 0,578 & 0,159 & 0,358 \\
\hline $\begin{array}{l}\text { Teoria das } \\
\text { restrições }\end{array}$ & M & 0,173 & 0,582 & 0,393 & 0,019 & 0,092 & 0,335 & 0,641 & 0,221 \\
\hline Valor presente & $\mathrm{T}$ & 0,322 & 0,224 & 0,458 & 0,597 & 0,860 & 0,319 & 0,685 & 0,343 \\
\hline $\begin{array}{c}\text { Tradicionais em } \\
\text { geral }\end{array}$ & $\mathrm{T}$ & 0,699 & 0,013 & 0,326 & 0,089 & 0,050 & 0,090 & 0,327 & 0,134 \\
\hline $\begin{array}{c}\text { Modernos em } \\
\text { geral }\end{array}$ & M & 0,219 & 0,212 & 0,680 & 0,013 & 0,115 & 0,017 & 0,049 & 0,003 \\
\hline
\end{tabular}

Fonte: Dados da pesquisa.

A hipótese $\mathrm{H} 1$ do estudo buscou testar se as características empresariais (faturamento, regime de tributação, idade, familiar ou não familiar, familiares de primeira geração ou gerações posteriores) implicam em diferentes níveis de uso dos controles modernos da Contabilidade Gerencial. Na Tabela 3, observa-se que não há diferenças estatisticamente significativas no uso dos controles gerenciais entre empresas mais jovens e mais antigas. Pavlatos (2012) também não encontrou relação significativa entre tamanho e idade da empresa com o desenho do SCG. Verifica-se ainda que a variável faturamento implica apenas em diferenças no uso do planejamento tributário, preço de transferência e kaizen.

O regime de tributação implica em diferenças estatisticamente significativas no uso de controles tradicionais. Assim, empresas do lucro presumido e do lucro real apresentaram intensidade de uso maior comparativamente às empresas tributadas pelo Simples Nacional. Tal resultado era esperado, pois empresas do lucro real geralmente possuem um número maior de operações, são maiores em faturamento, o que requer determinados tipos de controles.

No que concerne às características das empresas, apenas a comparação entre empresas familiares e não familiares implicou em diferenças no uso de um maior número de controles gerenciais. De modo geral, empresas familiares utilizam mais os controles modernos comparativamente às empresas não familiares. O desejo da família na manutenção do negócio sob o controle familiar, conforme apontado por Berrone, Cruz e Gomez-Mejia (2012), pode ser um dos fatores que contribuem para o uso de controles modernos da Contabilidade Gerencial.

Kappes e Schimid (2013) apontam que empresas familiares apresentam preferência para uma gestão orientada para o longo prazo, o que está condizente com o uso dos controles modernos da Contabilidade Gerencial, que visam um melhor uso dos recursos (Abdel-Kader \& Luther, 2006), concebem eventos históricos e futuros, informações financeiras e não financeiras (Hyvönen, 2005), a partir de orientação estratégica de longo prazo (Chenhall \& Langfield-Smith, 1998).

Na comparação entre gerações, observa-se que as empresas da primeira geração fazem uso maior de instrumentos tradicionais comparativamente a gerações posteriores. Isso pode sinalizar que as empresas familiares estão em busca de modernização das suas políticas, processos e controles. E que os fundado- 
res preferem o uso de controles tradicionais comparativamente as gerações posteriores. Giovannoni, Maraghini e Riccaboni (2011) preconizam que as práticas da Contabilidade Gerencial podem favorecer a transferência de conhecimento entre gerações, entre a família controladora e a equipe de gestão, ao representar e reproduzir as prioridades, valores e visão do empreendedor.

Assim, aceita-se parcialmente a $\mathrm{H} 1$. Os resultados mostraram diferenças no uso dos controles modernos nas características familiar e não familiar, familiar de primeira geração e gerações posteriores. Mas não houve diferenças estatisticamente significativas para faturamento, regime de tributação e idade da empresa.

Em relação às características dos gestores, nota-se que escolaridade, tipo de formação acadêmica e idade apresentam diferenças significativas no uso dos controles modernos da Contabilidade Gerencial. Assim, não rejeita-se a $\mathrm{H} 2$, de que há diferenças no uso dos controles gerenciais modernos nas empresas conforme o perfil dos gestores (idade, escolaridade e formação). Gestores mais jovens, com maior nível de instrução (escolaridade) e formados na área de negócios tendem a implementar e usar os instrumentos modernos da Contabilidade Gerencial. Inclusive, instrumentos tradicionais são utilizados em maior proporção quando os gestores possuem algum curso superior ou pós-graduação (especialização).

O planejamento estratégico e o orçamento, apontados com uma utilização reduzida na amostra, são usados principalmente por gestores com maior nível de escolaridade e com formação na área de negócios. Gestores com formação orientada para negócios tendem a ser mais familiarizados com o uso de controles gerenciais e são mais receptivos a mudanças dos sistemas existentes (Pavlatos, 2012). Portanto, as características dos gestores, como educação, afetam os seus processos de decisão, o que converge com a literatura denominada de escalões superiores por Hambrick e Mason (1984).

Esses resultados coadunam com os de Oliveira, Mueller e Nakamura (2000), Angelakis, Theriou e Floropoulos (2010) e Pavlatos (2012), de que a formação educacional dos gestores afeta seus processos de decisão e o uso de controles gerenciais. Young, Charns e Shortell (2001) asseveram que os gestores com melhor educação podem ser mais habilidosos na identificação de inovações a partir do fluxo de ideias a que estão expostos. Também convergem com as proposições de Naranjo-Gil, Maas e Hartmann (2009) e Pavlatos (2012) quanto à idade, de que gestores mais velhos são menos propensos a avaliar novas ideias e integrá-las de forma eficaz na tomada de decisões.

Depreende-se do exposto, que os gestores exercem importante papel na implementação e uso de controles gerenciais, o que coaduna com o estudo de Naranjo-Gil, Maas e Hartmann (2009), de que o uso de práticas modernas da Contabilidade Gerencial depende crucialmente da vontade do Chief Executive Officer (CFO) de se comprometer com a inovação e atuar como responsável dos novos sistemas. Os achados desta pesquisa revelam que o uso de controles gerenciais não é explicado exclusivamente por variáveis organizacionais ou individuais, incitando pesquisas adicionais.

\section{CONSIDERAÇÕES FINAIS}

Esta pesquisa buscou identificar as características das empresas e dos gestores que influenciam no uso de controles gerenciais. Os resultados evidenciaram que não há diferenças significativas entre o uso de instrumentos tradicionais e modernos da Contabilidade Gerencial. Os instrumentos são utilizados de acordo com a sua finalidade: controle de custos, avaliação de desempenho, suporte para tomada de decisão. Isso converge com o entendimento de Otley (1980), de que o uso de controles gerenciais dependerá da necessidade de cada organização em um determinado momento. 
Os testes não paramétricos de Mann-Whitney e Kruskal-Wallis, aplicados para analisar se características das empresas e dos gestores implicam em diferentes níveis de uso dos controles modernos da Contabilidade Gerencial, indicaram que há diferenças no uso dos instrumentos modernos da Contabilidade Gerencial em empresas familiares comparativamente com as não familiares. E que empresas com gestores jovens e ensino superior na área de negócios tendem a utilizar mais os controles modernos. Apenas o uso de alguns controles analisados isoladamente se diferencia pelo tamanho da empresa (faturamento e regime de tributação).

Estes resultados sugerem que as características das empresas estão relacionadas com o uso de determinados controles. Por exemplo, à medida que as empresas avançam no tempo, tendem a não apenas adotar controles tradicionais, ao controle financeiro e de custos são adicionadas preocupações com a gestão de valor. A pesquisa apontou que, em média, as empresas da amostra apresentam uso reduzido do planejamento estratégico e do orçamento. Porém, os testes apontaram que estes controles são utilizados com maior intensidade nas empresas cujos gestores apresentam curso superior e na área de negócios para o caso do planejamento estratégico. Portanto, escolaridade, formação e idade do gestor são as principais características que implicam em diferenças no uso de controles modernos.

Empresas familiares apresentaram situações diferenciadas de uso de controles gerenciais, principalmente os modernos, o que instiga pesquisas para possíveis explicações. Elementos elucidativos do uso de controles modernos podem ser: o desejo da família de manter o negócio (Berrone, Cruz \& Gomez-Mejia, 2012), a gestão orientada para o longo prazo (Kappes \& Schimid, 2013), a reprodução e transmissão das prioridades, valores e visão do fundador (Giovannoni, Maraghini \& Riccaboni (2011), os estágios do ciclo de vida organizacional (Moores \& Mula, 2010) e a preparação da sucessão (Hiebel, 2012; Chrisman, Chua \& Sharma, 2005).

As limitações deste estudo implicam parcimônia na interpretação dos resultados, já que a pesquisa se fundamentou na percepção dos respondentes às questões formuladas. Assim, aspectos subjetivos podem estar presentes nas respostas, direcionando-a para uma situação desejada na organização. Destaca-se ainda, que foram os gestores destas empresas que as classificaram como familiares ou não familiares, inclusive a literatura acerca do tema não contém um entendimento consolidado do que de fato caracteriza uma empresa familiar. Além disso, no estudo não foram examinados os benefícios do uso dos controles pesquisados.

Contudo, o estudo reforça a compreensão sobre as características que implicam em diferenças no uso dos controles gerenciais, tanto contextuais e organizacionais como dos gestores, e se constituem em antecedentes da implementação dos instrumentos da Contabilidade Gerencial. Assim, aspectos cognitivos, além dos econômicos, contingenciais e organizacionais, merecem ser contemplados em pesquisas futuras. Recomenda-se ainda que pesquisas futuras contemplem outras características dos gestores, principalmente de natureza comportamental. A investigação acerca das empresas familiares e sua relação com o uso de controles gerenciais também merece atenção por parte dos pesquisadores.

\section{REFERÊNCIAS}

Abdel-Kader, M., \& Luther, R. (2006). IFAC's conception of the evolution of management accounting: a research note. Advances in management accounting, 15(1), 229-247.

Abdel-Kader, M., \& Luther, R. (2008). The impact of firm characteristics on management accounting practices: a UK-based empirical analysis. The British Accounting Review, 40(1), 2-27. 
Angelakis, G., Theriou, N., \& Floropoulos, I. (2010). Adoption and benefits of management accounting practices: evidence from Greece and Finland. Advances in Accounting, 26(1), 87-96.

Becker, W., Ulrich, P., \& Staffel, M. (2011). Management accounting and controlling in German SMEs-do company size and family influence matter? International Journal of Entrepreneurial Venturing, 3(3), 281-300.

Berrone, P., Cruz, C., \& Gomez-Mejia, L. R. (2012). Socioemotional wealth in family firms: Theoretical dimensions, assessment approaches, and agenda for future research. Family Business Review, 25(3), 258-279.

Chartered Global Management Accountant ${ }^{\oplus}\left(\mathrm{CGMA}^{\oplus}\right)$. (2016). Princípios globais de contabilidade gerencial. Disponível em: <https://www.cgma.org/content/dam/cgma/resources/reports/downloadabledocuments/principios-globais-de-contabilidade-gerencial-1.pdf>. Acesso em: 03 jul. 2017.

Chenhall, R. H. (2003). Management control systems design within its organizational context: findings from contingency-based research and directions for the future. Accounting, Organizations and Society, 28(2), 127-168.

Chenhall, R. H., \& Langfield-Smith, K. (1998). The relationship between strategic priorities, management techniques and management accounting: an empirical investigation using a systems approach. Accounting, Organizations and Society, 23(3), 243-264.

Chrisman, J. J., Chua, J. H., \& Sharma, P. (2005). Trends and directions in the development of a strategic management theory of the family firm. Entrepreneurship Theory and Practice, 29(5), 555-576.

Chua, J. H., Chrisman, J. J., \& Bergiel, E. B. (2009). An agency theoretic analysis of the professionalized family firm. Entrepreneurship Theory and Practice, 33(2), 355-372.

Correia, R. B. (2010). Ciclo de vida organizacional e instrumento de gestão: uma investigação nas empresas baianas. Dissertação de Mestrado, Universidade Federal da Bahia, Salvador, BA, Brasil.

Davila, T. (2005). An exploratory study on the emergence of management control systems: formalizing human resources in small growing firms. Accounting, Organizations and Society, 30(3), 223-248.

Davila, T., \& Foster, G. (2005). Startup firms' growth, management control systems adoption and performance. In: AAA Management Accounting Section Meeting Paper

Davila, T., \& Foster, G. (2007). Management control systems in early-stage startup companies. The Accounting Review, 82(4), 907-937.

El-Shishini, H. M. (2017). The Use of Management Accounting Techniques at Hotels in Bahrain. Review of Integrative Business and Economics Research, 6(2), 64-77.

Fávero, L. P., Belfior, E. P., Silva, F. L. \& Chan, B. L. (2009). Análise de dados: modelagem multivariada para tomada de decisões. Rio de Janeiro: Elsevier.

Frezatti, F. (2005). Agrupamentos dos perfis da contabilidade gerencial no Brasil. Contabilidade, Gestão e Governança, 8(1), 9-39.

Giovannoni, E., Maraghini, M. P., \& Riccaboni, A. (2011). Transmitting knowledge across generations:The role of management accounting practices. Family Business Review, 24(2), 126-150. 
Gonzaga, R. P., Luz, A. T. M., Guimarães, T. N., \& Valerio Jr, V. B. (2010). Associação entre práticas de contabilidade gerencial e tamanho das empresas: um estudo empírico. Anais do Congresso ANPCONT, Natal, RN, Brasil, 4.

Guerreiro, R., Cornachione Júnior, E. B., \& Soutes, D. O. (2011). Empresas que se destacam pela qualidade das informações a seus usuários externos também se destacam pela utilização de artefatos modernos de contabilidade gerencial?. Revista Contabilidade \& Finanças, 22(55), 88-113.

Hambrick, D. C., \& Mason, P. A. (1984). Upper echelons: The organization as a reflection of its top managers. Academy of management review, 9(2), 193-206.

Helsen, Z., Lybaert, N., Steijvers, T., Orens, R., \& Dekker, J. (2017). Management control systems in family firms: A review of the literature and directions for the future. Journal of Economic Surveys, 31(2), 410-435.

Hiebl, M. R., Feldbauer-Durstmüller, B., \& Duller, C. (2013). The changing role of management accounting in the transition from a family business to a non-family business. Journal of Accounting \& Organizational Change, 9(2), 119-154.

Hyvönen, J. (2005). Adoption and benefits of management accounting systems: evidence from Finland and Australia. Advances in International Accounting, 18(1), 97-120.

Isidoro, C., Facci, N., Espejo, M. M. D. S. B., \& Garcias, P. M. (2012). A utilização de artefatos de contabilidade gerencial em cooperativas agropecuárias. Revista de Contabilidade da UFBA, 6(2), 39-55.

Kappes, I., \& Schmid, T. (2013). The effect of family governance on corporate time horizons. Corporate Governance: an International Review, 21(6), 547-566.

Moores, K., \& Mula, J. (2000). The salience of market, bureaucratic, and clan controls in the management of family firm transitions: Some tentative Australian evidence. Family Business Review, 13(2), 91-106.

Naranjo-Gil, D., Maas, V. S., \& Hartmann, F. G. (2009). How CFOs determine management accounting innovation: an examination of direct and indirect effects. European Accounting Review, 18(4), 667-695.

Nuhu, N. A., Baird, K., \& Appuhami, R. (2016). The Association between the Use of Management Accounting Practices with Organizational Change and Organizational Performance. Advances in Management Accounting, 26(1), 67-98.

Oliveira, A. G. D., Müller, A. N., \& Nakamura, W. T. (2000). A utilização das informações geradas pelo sistema de informação contábil como subsídio aos processos administrativos nas pequenas empresas. Revista FAE, 3(3), 1-12.

Otley, D. (1980). The contingency theory of management accounting: achievement and prognosis. Accounting, organizations and society, 5(4), 413-428.

Otley, D. (1999). Performance management: a framework for management control systems research. Management Accounting Research, 10(4), 363-382.

Oyadomari, J. C., Cardoso, R. L., Mendonça Neto, O. R., \& Lima, M. P. (2008). Fatores que influenciam a adoção de artefatos de controle gerencial nas empresas brasileiras: um estudo exploratório sob a ótica da teoria institucional. Revista de Contabilidade e Organizações, 2(2), 55-70.

Pavlatos, O. (2010). The impact of firm characteristics on ABC systems: a Greek-based empirical analysis. Performance Measurement and Management Control: Innovative Concepts and Practices, 20 (1), 501-527. 
Pavlatos, O. (2012). The impact of CFOs' characteristics and information technology on cost management systems. Journal of Applied Accounting Research, 13(3), 242-254.

Pavlatos, O., \& Kostakis, H. (2015). Management accounting practices before and during economic crisis: evidence from Greece. Advances in Accounting, 31(1), 150-164.

Raupp, F. M., Martins, S. J., \& Beuren, I. M. (2006). Utilização de controles de gestão nas maiores indústrias catarinenses. Revista Contabilidade \& Finanças - USP, 17(40), 120-132.

Reginato, L., \& Guerreiro, R. (2011). Um estudo sobre a associação entre modelo de gestão e controles gerenciais em indústrias brasileiras. Revista Universo Contábil, 7(2), 6-27.

Reis, A. M., \& Teixeira, A. J. C. (2013). Utilização de artefatos de contabilidade gerencial nas sociedades cooperativas agropecuárias de Minas Gerais e sua relação com porte e desempenho financeiro. Revista de Educação e Pesquisa em Contabilidade, 7(4), 355-371.

Seal, W. (2006). Management accounting and corporate governance: An institutional interpretation of the agency problem. Management Accounting Research, 17(4), 389-408.

Soutes, D. O. (2006). Uma investigação do uso de artefatos da contabilidade gerencial por empresas brasileiras. Dissertação de Mestrado, Universidade de São Paulo, São Paulo, Brasil.

Speckbacher, G., \& Wentges, P. (2012). The impact of family control on the use of performance measures in strategic target setting and incentive compensation: a research note. Management Accounting Research, 23(1), 34-46.

Sulaiman, M. B., Ahmad, N. N. N., \& Alwi, N. (2004). Management accounting practices in selected Asian countries: a review of the literature. Managerial Auditing Journal, 19(4), 493-508.

Teixeira, A. J. C., Gonzaga, R. P., Santos, A. V. S. M., \& Nossa, V. (2011). A utilização de ferramentas de contabilidade gerencial nas empresas do Estado do Espírito Santo. Brazilian Business Review, 8(3), 108-127.

Valeriano, C. E. B. (2012). Ciclo de vida organizacional e artefatos de contabilidade gerencial: uma investigação nas 250 pequenas e médias empresas que mais cresceram no Brasil entre 2008 e 2010. Dissertação de Mestrado, Universidade de São Paulo, São Paulo, Brasil.

Yalcin, S. (2012). Adoption and benefits of management accounting practices: an inter-country comparison. Accounting in Europe, 9(1), 95-110.

Young, G. J., Charns, M. P., \& Shortell, S. M. (2001). Top manager and network effects on the adoption of innovative management practices: A study of TQM in a public hospital system. Strategic Management Journal, 22(10), 935-951. 